\title{
Research on the Safety Risk Analysis Method for Sports Food Based on Open Food Information
}

\author{
Fan Mingkang* and Xu Xiaozhen ${ }^{*}$
}

Institute of Physical Education, Gannan Normal University, Jiangxi, China

\begin{abstract}
Sports health food demand is increasing year by year. But facing wide variety of health foods on the market and wall-to-wall advertising, the safety risk of sports food remains a problem. Based on the open food information, this paper aims at prompting an optimizing safety risk analysis method for sports food. This paper conducts a deep research on the sports food security issues from public management crisis management theory, institutional economics and other theories; and based on the food security crisis management it carried a research on mechanism in order to put forward feasible policies and suggestions on sports food safety problem for local government.
\end{abstract}

Keywords: Open food information, optimization, safety risk analysis method, sports food.

\section{INTRODUCTION}

Food safety regulation is one of the most important fields within government regulation in modern times, which is also a worldwide challenge. Government regulation originated in anti-monopoly regulation and economic regulation in U.S.A. in the late $19^{\text {th }}$ century. With the further development of the modern industry, adverse impact resulted from enterprise production and business operation has brought more and more serious problems. Government regulation extends to the field of social regulation such as environmental pollution, food safety, and occupational safety. Under the wave of new liberalism, economic regulation has become deregulation, while social regulation has become under tighten control. In recent years, food scares are common in China, which is related to government regulation performance more than social contradictions and problems [1]. Solving food safety in China doesn't lie in the establishing or enhancing of regulation, but in the effectiveness of regulation system itself [2].

In today's world, with the continuous improvement of the economic development and material life, nutrition, health, quality and security of food have become the focus of increasing concern to consumers [3]. The organic food, green food, health food, dietary supplements, food and nutrition supplements, special nutritional food, functional food, special medical food, sports nutrition of various countries, have become a new growth point of food industry in recent years. The current global health food accounts for $5 \%$ of total food sales, amounted to billions of dollars, and it grows fast every year. USA sales of health food products currently are billions of dollars. Japanese healthy food sales for a few one hundred billion yen in recent years and there are more than 3000 kinds of health food.
There are more than 2000 kinds of health food in Europe, and sales to an annual rate of $17 \%$. Chinese health food in 2010 reached 100 billion yuan, and will reach to 100 billion yuan [4]. From the development trend, living standards improve, people will inevitably focus on living and quality of life, and to the health of the consumer product transfer, and thus, spending money on health is inevitable [5]. United Nations Industrial Programmer noted that the two sunrise industries in the 21 st century are electronic-based information technology industry and life sciences development-based health industry. And health care industry and the pharmaceutical industry it is the most potential for the development of the life sciences industry [6].

After the 2008 Beijing Olympic Games, the central government puts forwards to achieve the competitive sports and mass sport conformity development [7]. August 2009, the State Council promulgated the "National Fitness Regulations". Future government authorities in the provision of public goods and services will also sport a great effort, to ensure people's basic needs physical exercise. In addition there is still a lot of diversification, personalized sports demand due to the different income levels caused. In this context, China's national fitness campaign increasingly active groups in physical exercise, more and more people's health awareness gradually increased, the demand for health food has also increased. But facing wide variety of health foods on the market and wall-to-wall advertising, people often don't know how to choice sports nutrition and health food. Safety of health foods has attracted the attention of governments and international organizations highly. So strengthening the health management of food hygiene is an important topic on the health aspects of food safety in China [8].

\section{THE BACKGROUND OF SPORT FOOD SAFETY IN CHINA}

Health food safety is a major health and social stability of the peoples, and has become the focus of the world's governments and the public increasingly concerned. Today 
China's rapid economic development and rising living standards, we should actively establish sound health food safety control security system, strengthening government health food safety supervision, the establishment of health food safety control detection and early warning systems to ensure that our people quality and safety of health food, narrowing the gap with the world's advanced countries in terms of food safety, health, and promote the improvement of China's overall level of health food industry has a very important practical significance.

Currently, the food safety risk analysis is internationally acknowledged as a main method to manage food safety. To analyze risk is to reduce risk in the maximum limit following three procedures ranging from risk evaluation, risk management to risk communication. Among which risk evaluation is the scientific basis and key procedure of risk analysis. By involving a few links, such as, raw material, storage, processing, packing, circulation sales and consumption, this thesis makes a risk identification of food safety. It also finds up potential risk threats and analyzes risk source and risk factors in order to efficiently evaluate risk. A ranking demonstrates that microbial food poisoning heads the list of all kinds of factors which influence Chinese food safety [9].

On a basis of analysis of China's food safety risk assessment current situation, China's food safety risk assessment system should be structured considering three principles and six elements. Three principles are to be institutional independent, to be scientific creative, to be administrative transparent. Six elements are to establish a consolidated independent institute, to perfect operating mechanism of food safety risk assessment, to construct well-arranged food safety risk assessment legal system, to set up efficient informational communication channel, and to play the key supporting role of food safety risk assessment to food safety supervision system [10].

It is necessary to learn from some developed countries and region, such as, European Union, United States and Japan. What we learn is their advanced and successful experience of food safety supervision. The parts that fit China's situation should be taken, and to make it ours. The necessity for making novelty in the model of our food safety supervision system reveals. With a consideration of Chinese legal system on food safety supervision and current supervision mechanism of food safety, this thesis analyzes the problems revealed in our food safety supervision legal system and supervision mechanism. Through a deep study of the theory of lemon market, it is shown that the major reason that has raised the issue of food safety is the converse selection which is caused by an information asymmetry between food producers and food consumers. And then, a phenomenon of lemon market has been occurred. Due to the existence of market failures in safely supplying foods, it is important to rely on governmental surveillance to make up the market functional failures. However, what we are facing are a severe government failure and a declined public trust. It calls stronger and harsher measures to enhance regulation performance.

Our national food safety law was published long time ago. Restricted by the legislation background, facilities, information technology, idea and other factors, some drawbacks are inevitable. Five main problems are proposed as a reference to the new legislation and the correction is welcome if there are any inappropriate points. The system is not complete. Food safety Law regulates food produce, processing, storage, transportation, distribution and marking but does not includes plantation, breeding, harvesting, collecting and hunting. Experience of many countries and international practice show that: to provide more efficient protection to consumers, it is necessary to consider all the cru nodes from manufacturing to marketing and supplying as an integrated whole because each part is possible to produce effects on food safety.

The serious safety drawbacks include: the procedure administration of "from field to fork" is not included; the food safety control system is not complete; "adjust from the very beginning" is not included; and the safety of primary edible agricultural products are not regulate. Considering that Agricultural Products Quality Safety Law will be enacted soon, the new Food Safety Law should take the corresponding authorization and connection into account. The contents are not comprehensive. Those legislation points, which are widely adopted (or will be adopted) by international society and developed countries and are proved to be effective, are not included in food hygiene law such as that "government should take up the full responsibility regarding food safety"; that "enterprise should take up the first responsibility of food safety"; "the honesty principle and moral standards of food industry and business"; "food safety risk analysis and assessment"; "food safety alarm and prevention"; "food safety emergence control"; "food safety tracing system"; "recalling back and treatment of unsafe food"; "market entrance permission" "responsibility judgment and compensation in serious food safety accidents"; "comprehensive management, assessment and publication of food safety information"; and "administration of food safety certification and accreditation". The new food safety law should include all those advance systems, theories and methods to realize the idea of "scientific administration".

It was impossible for Food Safety Law to see the development of government structure reform, to reflect the present situation of food administration' to divide the rights and responsibilities among different departments clearly, and to spare the development space for tomorrows at that time. Tens of years have passed; great reforms have taken place in food safety administration system and the model of "multiple agencies system" combining comprehensive administration and department regulation has also formulated. All this should be recognized and guaranteed by the new law on the basis of dividing clearly the rights and responsibilities among all the administration departments. International experiences show that "strengthening the coordination of safety management system reform. Whether the single agency system practiced by those countries such as Canada, Denmark, Ireland, Australia, and EU, or the multiple agencies system practiced by USA, Japan, or the integrated system practiced by some other countries, all have advantages and disadvantages regarding development and stabilization.

\section{THE REALIZATION OF SPORT FOOD SAFETY ANALYSIS BASED ON OPEN FOOD INFORMATION}

In as early as 1970s, European countries have established a Rapid Alarm System for Food and Feed (RASFF). As a 


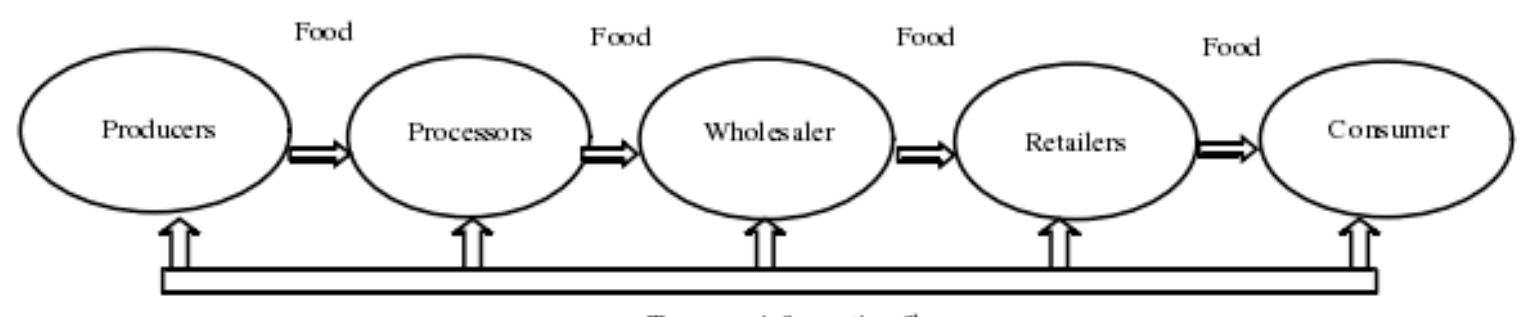

Two-way information flow

Fig. (1). Logistics and information flow of food traceability system.

huge food rapid alarm and emergency system, RASFF covers European Food Safety Authority (EFSA), European Food Management Committee and member countries of European Union. When food safety problems that may endanger human health have appeared in member countries of EU or third party countries, RASFF will be started up immediately to inform all EU countries about the problems so as to prevent unqualified foods from entering those countries. In addition, EU countries can advise EU Commission to start the alarm system when discovering there is a food safety crisis in certain area. The commission of RASFF will confirm the information immediately and inform EU countries about the crisis if it has been verified as true.

Track the food supplying chain make food information traceable; and processing chain and record them in details; create a traceability system to realize an open create profiles to and transparent procedure that goes "from farmland to dining tables" so that foods bought by consumers can be guaranteed as safe. In specific, food information traceability system is a complete and closed procedure: Tracking, recording and filing every segment of foods from production; creating a detailed and continuous information flow; tracking and recording every segment from production to final consumption to facilitate tracking. Such management method is helpful for confirming every segment of food production, as well as their sources and usages. In addition, it can track inspected products quickly and accurately while monitoring and analyzing the influence of food on human being and environment timely and accurately.

By referring to the food traceability model of European Union, this paper has established a bidirectional information flow model for food information tracking in China (as shown in Fig. 1). In the tracking system, food information flow is moving in both positive and negative directions; food information has been profiled since production and later segments are also profiled in sequence; the profile information will form an information flow that moves in positive direction and backtrack in negative direction to form a bidirectional flow model. The advantages of the bidirectional information flow are: real-time tracking on product usages; sending information to downstream segments quickly and accurately and releasing alarming information when a problem is identified in previous segments so as to call back all unqualified food in time; a realization of tracking when a safety problem has appeared in the next segment so as to identify the segment where the problem has appeared quickly and accurately.

Upon a reference to the experience of opening food information of European Union, measures to construct a food safety credit system in China include:
(1) Applying advanced communication technology to establish a quick and accurate information communicating and reporting system to speed up information broadcasting and improve the accuracy.

(2) Governmental management departments should play a role of safeguarding information publication and take necessary measures to rectify information island, blocked information transmission and unbalance information acceptance. In addition, the management departments should provide related information services, as well as latest laws, regulations, policies, standards and other related information, for related enterprises and the public through various channels for free; finally, the departments should establish and release credit records on all enterprises, which is shown in the following Fig. (2).

(3) Establishing information release regulations and standards for related industries formulating access systems for various industries and supervising their enforcement.

From the food safety informatization management system of European Union, we can discover that tracking, monitoring and alarming food supplying chains and food borne diseases upon modern information technology so as to react to safety risks quickly and undertake emergency management is a very critical. It is necessary to establish a sound food safety emergency reaction information system. Upon that, this paper has constructed a model of food safety emergency reaction system in China which is shown in Fig. (3).

From the analysis before, some suggestions about improving China's sports food safety may be given which includes: 1. Functions and roles of systematic regulation of food safety; 2. Intensification of the responsibility system of China's public organizations for food safety; 3 . Strengthening the building of various systems of governmental food safety regulation. Specific recommendations are as follows: (1) Improving organizational leadership and clarifying regulatory responsibilities of the governments at all levels; (2) Improving coordination of governmental regulations and emergency response systems; (3) Establishing food safety information platforms and adopting the "red list" and "black list" systems; (4) Strengthening the social supervision by public opinions and incentive reporting system; (5) Realizing webbased systems of China's food safety regulation.

\section{CONCLUSION}

This paper conducted a deep research mainly based on the sport food security issues based on open food information. Based on the food security crisis management it carried a research on mechanism in order to put forward feasible 


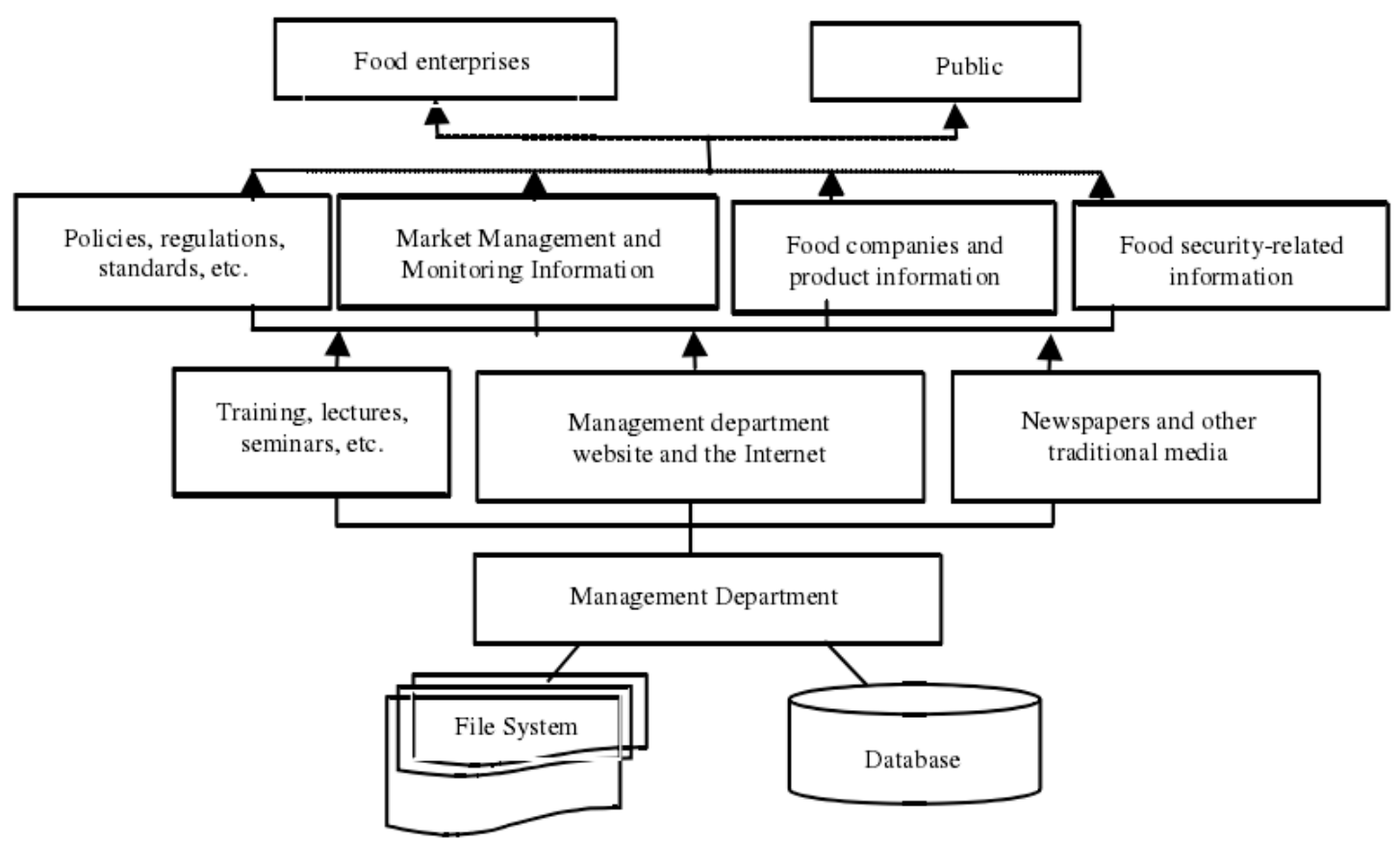

Fig. (2). Food safety information releasing and disclosing system.

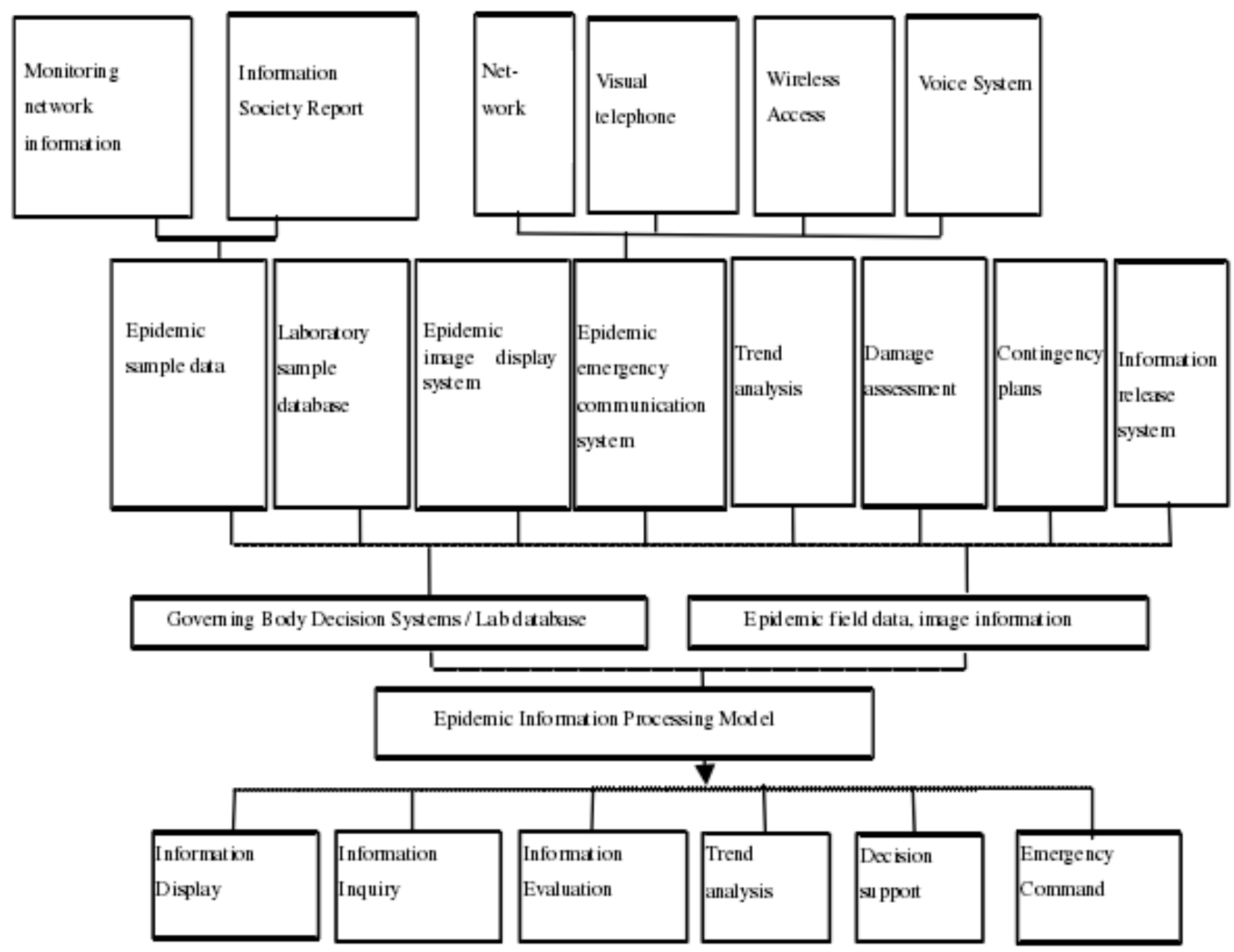

Fig. (3). Model of food safety emergency reaction system in China. 
policies and suggestions on food safety problem for local government. The open sport food safety information system based on data flow technology is also constructed in this paper. The system can be used to measure the safety risk and do the analysis for sport food. By analyzing and referring to sport food safety risk model of European Union, this paper has explored an idea on practicing food safety risk model in China. The analytic demonstration in this paper has proved that it is possible to introduce the idea of risk model into food safety management of China. Meanwhile, qualitative analysis is a major analysis method applied in this paper though a lot of quantitative analyses required for food safety management are not mentioned. Therefore, the author will focus on the two points to further push and perfect the study content in later studies.

\section{CONFLICT OF INTEREST}

The authors confirm that this article content has no conflict of interest.

\section{ACKNOWLEDGEMENTS}

This work is supported by 2013 scientific research project of Beifang University of Nationalities (2013XYZ021), institute of information and system computation science of Beifang University (13xyb01).

\section{REFERENCES}

[1] D.M. Lambert, "Food industry investment flows: implications for rural development," The Review of Regional Studies, pp. 140-162, 2006.

[2] D. Pick, "Product differentiation and asymmetric information in agricultural and food market: defining the role for government: discussion," American Journal of Agriculture Economics, vol. 3, pp. $742-743,2003$.

[3] G. Hendrikse, "Ownership structure in agrifood chains: the marketing cooperative," American Journal of Agriculture Economics, pp. 104-119, 2002.

[4] H. Hasler, "Position of the american dietetic association: functional foods," Journal of the American Dietetic Association, vol. 2, pp. 814-826, 2004.

[5] P. Coppens, "European regulations on nutraceuticals, dietary supplements and functional foods: A framework based on safety," Toxicology, vol. 4, pp. 59-74, 2006.

[6] P. J. Jones, "Functional food development: concept to reality, "Trends in Food Science \& Technology, vol. 2, pp. 387-390, 2007.

[7] R. Ryder, "Procurement best practice in the food industry: supplier clustering as a source of strategic competitive advantage," Supply Chain Management: An International Journal Supply Chain Management: An International Journal, vol. 3, pp. 164-171, 2003.

[8] L. Wang, and S. K. Zhao, "The data warehouse support the research to commercial bank CRM," Information Science, vo1. 26, no. 3, pp. 400-403, 2008.

[9] H. Wang, "The design of data warehouse of the civil aviation revenue manage system. computer applications and software, "vo1.21, no. 6, pp. 49-50, 2004.

[10] P. J. Xu, "Data Warehouse \& Decision Support System," Beijing: Science Press, 2005. 